\title{
Robotic Process Automation (RPA) Implementation Drivers: Evidence of Selected Nordic Companies
}

\author{
Damian Kedziora, Hanken School of Economics, damian.kedziora@hanken.fi \\ Arja Leivonen, Jyväskylä University of Applied Sciences, arja.leivonen@student.jamk.fi \\ Wojciech Piotrowicz, Hanken School of Economics,wojciech.piotrowicz@hanken.fi \\ Anssi Öörni, Abo Akademi, anssi.oorni@abo.fi
}

\begin{abstract}
Along the continuous transformations of enterprises, centralized service delivery models have been transitioning from an offshore employee sourcing to digital sourcing. Deploying software robots with robotics process automation (RPA) became one of the most important and fastest growing technologies in the recent years. In this research, the blended qualitative approach was applied, as a survey was followed by interpretative interviews and narrative analysis. This exploratory, empirical study discusses the key drivers behind RPA implementations (financials, employee impact, risks) identified among experts involved in the deployment of intelligent automation solutions at selected Nordic enterprises. The findings highlight the focus on the operational benefits like releasing employees from the most monotonous, nonvalue adding assignments, strengthening enterprise efficiency, compliance, and quality. Notably, the strategic and external (customer) impacts were not at the core of the RPA decision-making process among the studied case companies. The findings suggest that RPA is mainly perceived as an operational tool to automate and improve internal processes with little consideration of its strategic and external impact, including impact on customers and service quality. This is in line with the approach to the way of how benefits are calculated, looking mainly at savings on labor costs.
\end{abstract}

Keywords: Robotic Process Automation, RPA, software, robots, bots, digital, hybrid, workforce, finance, accounting, business process, risks, benefits

\section{Introduction}

For the past few decades, globalized services market has been subject to dynamic digital transformations. Intensive relocations of various business functions observed in Nordic and Central Europe since 1990s, allowed many enterprises to harmonize and streamline their business processes (Piotrowicz and Kedziora, 2018). The next step, aiming at further improvement of operational processes was to automate some of them with Robotic Process Automation (RPA) (Asatiani and Penttinen, 2016). This technology emerged over past few years as disruptive and one of the strongest growing (Harrast, 2020). It became a substantial part of digital transformation at numerous enterprises, understood as the use of information technology (IT) to radically improve operational performance (Horlacher and Hess, 2016). Introduction of RPA over cloudbased and client systems, following the offshore transitional effort, often facilitated strategic transformations aimed at shifting the engagement of human workforce from performing manual tasks to supervisory control in the long run (Güner et al., 2020). Automation can be perceived as another key breakthrough in the evolution of enterprise information systems (IS) and human-computer interaction (HCI) (Gregory and Nussbaum, 1982), following such technological disruptions as mobile software design, cloud computing, blockchain, collaborative networks $(\mathrm{CN})$ and internet of value (Afsarmanesh et al., 2007) It has 


\section{Issues in Information Systems}

Volume 22, Issue 2, pp. 21-40, 2021

been embracing competitive evolution of many companies, responding to so called 'IT productivity paradox', as the information age that was supposed to free employees from the mundane tasks (Uwizeyemungu et al., 2018), has still made many workers feel more and more busy and stressed than ever before. The productivity growth rate has been steadily declining since 2000 (Byrne et al., 2013), which is highlighting the unfulfilled contribution of IT to resource productivity that is the key to each enterprise's success (Beheshti and Beheshti, 2010). Therefore, to avoid the risk of the growth chasm, it is important to study and effectively manage the impact of technological disruptions on the enterprise workforce (Lyu and Zhang, 2017). To overcome the burden of overwhelming tasks, enterprises shall aim at applying digital transformation across the entire value chain, reinventing all processes towards the improved sustainability of disconnected technology and processes (Anthony, 2020). Transforming onto new digital business models, many enterprises already applied hybrid deliveries in various operational domains, combing multiple organizational forms and governance modes (Madakam et al., 2019). Such hybrid organizing can be defined as structures, activities, meanings, and processes by which companies and societies combine aspects of various organizational forms (Battilana and Lee, 2014). Software robotics became increasingly involved in executing tasks alongside people, so the expression 'hybrid workforce' is already in use in regards people and software bots working together (Cewe et al., 2018).

The concept of automation in enterprise information systems has its roots in the workflow automation and screen scraping tools introduced in the early 1990s (Jung et al., 2015; Jeston, 2018), yet the term has started to be in wide use over the past 10 years (Willcocks et al. 2015). With a compound annual growth rate (CAGR) of 29\% during 2017-2023 (Reuters, 2018), the number of software bots in the world is estimated to reach 4 million by 2021 (Forrester, 2018). RPA enabled many enterprises where there is still lots of manual, standardized tasks to be relatively quickly deployed and solve some challenged faster and cheaper than traditional, more demanding cross-system integration (May et al., 2009). In the latest use cases reported, robotic software has been evolving onto 'intelligent automation', getting enhanced with cognitive elements of other technologies from artificial intelligence (AI) domain, such as optical character recognition (OCR), natural language processing (NLP), machine learning (ML), as well as blockchain (Anagnoste, 2018; Tang et al., 2019). This type of software acts as a strategic digital transformation lever for global business services (Willcocks et al., 2017), helping enterprises to offer improved, agile value to customers (Aguirre and Rodriguez, 2017). In the next few years, it shall release millions of employees from boredom, enabling their job profiles to transform onto more creative, highly reliant on talent, empathy, negotiation, and customer consultancy (Hallikainen et al., 2018). Nevertheless, the need for human workers remains obvious for more complex tasks based on reasoning and empathy, including arts, management, negotiations, finance and accounting consultancy, bringing people to perform hand in hand with software robots as hybrid workforce (Syed et. al 2020). Therefore, RPA is certainly among technologies that will change the social and corporate landscapes of highly globalized services, as well as their impact on organizational financials, operational processes, development, customers, and growth (Leopold et al., 2018).

Since the decision making process related to the deployment of RPA has not yet been studied extensively, the authors aimed at exploring the field based on reviewing academic sources and information reported by multiple commercial sources, as well as validating empirical data gathered from different RPA suppliers and executive business experts. The goal of this exploratory research is to examine the key decision-making factors related to the implementation of RPA at Nordic companies, in the context of organizational setup and culture. Therefore, the paper addresses four research questions:

Q1: What was the role of IT department in RPA development?

Q2: What decision criteria are used for RPA development?

Q3: What are the risks related to RPA implementation?

Q4: How independently do software robots in process automation work? 


\section{Literature}

Robotic Process Automation (RPA) can be described as a type of software acting as "an infinitely scalable virtual human that can be instructed very quickly in order to carry out operational procedures at the speed of a machine" (Lacity and Willcocks, 2016), interacting with legacy IS via graphic user interfaces (GUI), in a similar way as a human worker (Rajesh et al., 2018). Therefore, it is most suitable for tasks where the data needs to be taken from one application or system, transformed, and manipulated according to the welldefined and structured rules, and then uploaded to another system (Bygstad, 2016). The word "robotics" is originating from the engineering and science, including such domains electronics engineering, computer science, mechanical engineering, (Hong et al., 2016) and refers to the electromechanically designed machine that is programmable by a computer and can carry out automatically a complex series of actions (Brady, 1985). RPA though, can be referred to as a perfect example of lightweight IT, or middle-ware (Issa et al., 2009) that has become one of key means of process improvement and co-creating digital customer value in the past few years (Kedziora and Kiviranta, 2018). The term started to be used as an umbrella term for toolset that operates at GUI level for various applications in the similar way that a human worker would do (van der Aalst et al., 2018), using existing computer systems to perform data manipulation, transaction processing, and communication across systems. Software robot can execute tasks on multiple processes and business functions in different time slots. For instance, HR process in the morning, finance process in the afternoon and administrative reporting process in the evening (Patil et al., 2019; Ranerup and Henriksen, 2019). RPA could be linked and used together with other technologies, such as Image Recognition and Optical Character Recognition (OCR) to optimize digitizing processes and adapt to changing web services without requiring intervention from a human worker (Anagoste, 2018).

Before automating any process, the first step in its modelling is to determine what is the context of the task, and to describe the purpose of the model, as well as the situation for which our modelling is carried out (Leno et al., 2018). Business process is a set of activities that manipulates and transforms single or more inputs and then generates output (Harmon, 2014.; Suri, 2017) Information on the current process's state is gathered from the existing execution scenario to illustrate the process's implementation (Martinsuo and Blomqvist, 2010). Formal process diagrams can be referred to as activity diagrams, process maps, workflow diagrams or process blueprints (Aldin and Cesare, 2011). The level of process modelling determines how detailed and precise the descriptions are (Luukkonen et al., 2012), starting from top level, such as map of the section of supply chain, finishing with activities and individual tasks. The process must be defined and standardized before it can be automated, also process optimisation is an important step, such as elimination of non-value-added activities and reduction of decision points (Zhang and Liu, 2018). Breaking processes down into smaller blocks that consist of common sub-processes and tasks can help in effective and consistent re-use of such blocks across multiple processes (Lowes et al., 2017). The more advanced way of extensive process analysis is the process mining, understood as a business method where data gathered from multiple sources is used for business analysis (Shelke, 2018). Process mining is an effective method for extending or enhancing existing process logics by using and exploring additional data from the recorded logs (Kerremans, 2019). With contemporary data mining methods, process data left unused is brought to the forefront, as it contains the exact information on how a business process is carried out (Nominacher, 2018). Using business process analysis, it is possible to identify the areas in the company where a lot of effort is still wasted in repetitive tasks, and such tasks can be partly or fully automated with use of RPA (Kerremans, 2018).

According to the latest report on the Finnish RPA Market conducted by Capgemini, the biggest benefit from RPA is perceived in the business areas of Customer Service, Accounting and Finance, Human Resources, Production and Information Technology (Capgemini, 2020). The RPA candidate processes should be possible to break down into small, rule-based and straightforward steps that are highly 


\section{Issues in Information Systems}

Volume 22, Issue 2, pp. 21-40, 2021

standardized with minor exceptions occurring while completing a task. It should not require creativity, complex interpretation skills, nor subjective judgment, but prone to human errors, and including critical functions since the cost of automation should be lower than the cost of errors related to business impact (Fung, 2014; Haliva, 2015; Seasongood, 2017). Workflow automation software can also be used to aid in capturing and scraping certain data fields of interest, such as invoice total amount, tax value, customer contact information, and then translate them into company's database, as well as notifying the relevant employee. Such software eliminates the need for manual data entry, in the same time increasing order fulfilment rates, bringing additional advantages of increased efficiency, speed, and accuracy (Ostdick, 2016).

RPA platforms are commonly built of three elements: deployed package that is commonly called 'software robot', programming tool (studio) and controller (orchestrator) (Barnett, 2015). A programming tool functions by intuitive process mapping (with objects and activities taken from 'drag-and-drop' libraries'), in a language used for the coding architecture that is commonly the .NET / C\# frame (van der Aalst et al. 2018). The controller/orchestrator provides workflows and controls to govern the process of creating, reviewing, updating, approving, testing, and then deploying tasks to the software robots. Controllers assign tasks to grouped or single robots to execute, and monitors/reports on their performance (Swanson, 2019). Some solutions support integration with other systems over open application programming interfaces (APIs) (Piao et al., 2010), mail servers, and web services to aid the user management (BluePrism, 2019). The summary of core capabilities and functions for RPA include categories such as Data Collection, Data Processing and Activities (Table 1).

Table 1: Core functions and capabilities for RPA (based on Lowes et al., 2017; Lawson, 2016, Güner et al.,

2020; Suri et al., 2017)

\begin{tabular}{|c|c|}
\hline CATEGORY & RPA FUNCTIONS AND CAPABILITIES \\
\hline $\begin{array}{l}\text { DATA } \\
\text { COLLECTION }\end{array}$ & $\begin{array}{l}\text { 1. Opening emails and attachments } \\
\text { 2. Scraping data from the web } \\
\text { 3. Capturing digital data from source systems } \\
\text { 4. Collecting social media statistics } \\
\text { 5. Logging into web/enterprise applications } \\
\text { 6. Obtaining human decisions or input via } \\
\text { email/workflow }\end{array}$ \\
\hline $\begin{array}{l}\text { DATA } \\
\text { PROCESSING }\end{array}$ & $\begin{array}{l}\text { 7. Copying and pasting data } \\
\text { 8. Filling forms } \\
\text { 9. Moving files and folders } \\
\text { 10. Reading and writing to databases } \\
\text { 11. Merging data from multiple places } \\
\text { 12. Extracting structured data from documents } \\
\text { 13. Extracting and reformatting data into reports } \\
\text { or dashboards } \\
\text { 14. Generating and distributing reports } \\
\text { 15. Validating or manipulating data based on } \\
\text { if/then logic } \\
\text { 16. Transferring or posting digital data to target } \\
\text { systems }\end{array}$ \\
\hline
\end{tabular}




\section{Issues in Information Systems}

Volume 22, Issue 2, pp. 21-40, 2021

\begin{tabular}{|l|l|}
\hline & $\begin{array}{l}\text { 17. Making calculations } \\
\text { ACTIVITIES }\end{array}$ \\
$\begin{array}{l}\text { 18. Connecting to system APIs } \\
\text { Starting work based on a schedule or } \\
\text { electronic trigger }\end{array}$ \\
\hline
\end{tabular}

There are multiple benefits from the RPA implementations that facilitated the rapid growth of software robotics over the past few years. According to the Lhuer's interview with Leslie Willcocks (2017), the return of investment (ROI) ranges between 30 and 200 percent during the first year, the customer service is improved, as the staff has more time to focus on customer interaction, while at the same time employees can benefit from reduced workload, as providing more value for customers in critical in current business relationships (Shehata and Montash, 2019). Therefore, the implementation's success can be measured in terms of the number of hours that have been given back to the business (Ratia et a., 2018). It is also bringing release from boring tasks to the employees, who can now concentrate on the value-added tasks (Fernandez and Aman, 2019), in the same time requiring the organization to prepare complex HR-strategy related to the re-skilling employees and allowing them to use their free time on personal development (Šimek and Šperka, 2019). RPA Centre of Excellence (RPA CoE), being the unit that owns and manages RPA transition at an enterprise, can therefore deliver benefits in the four key areas identified in Table 2 (cost reduction, productivity enhancements, improved customer service, and impact on employees), and the benefits of the implemented system are still holding key place in the understanding and decision making at multiple organizations (Cho and Jung, 2018).

Table 2: Categories of RPA Benefits (based on Lawson, 2016; Sengupta et al., 2017; Lowes et al., 2017; Singh

2018; Jimenez and Ramirez, 2019)

\begin{tabular}{|c|c|}
\hline CATEGORY & RPA BENEFITS \\
\hline $\begin{array}{l}\text { COST } \\
\text { REDUCTION }\end{array}$ & $\begin{array}{l}\text { 1. Total Full Time Equivalent savings and } \\
\text { cost reduction } \\
\text { 2. Removal of non-value-added processes } \\
\text { 3. Reduction in training cost }\end{array}$ \\
\hline $\begin{array}{l}\text { PRODUCTIVITY } \\
\text { ENHANCEMENT }\end{array}$ & $\begin{array}{l}\text { 4. Flexibility to scale capacity } \\
\text { 5. Work around the clock } \\
\text { 6. Detailed data capture } \\
\text { 7. Better management information } \\
\text { 8. Advancing digital transformation practises } \\
\text { in organizations of both public and private } \\
\text { sectors }\end{array}$ \\
\hline $\begin{array}{l}\text { CUSTOMER } \\
\text { SERVICE } \\
\text { IMPROVEMENT }\end{array}$ & $\begin{array}{l}\text { 9. Processing lead-time shortening } \\
\text { 10. Accuracy in handling customer orders } \\
\text { 11. Customer satisfaction improvement } \\
\text { 12. Quality improvement } \\
\text { 13. Compliance improvements } \\
\text { 14. Advancing organization practises }\end{array}$ \\
\hline
\end{tabular}




\section{Issues in Information Systems}

Volume 22, Issue 2, pp. 21-40, 2021

\begin{tabular}{|l|l|}
\hline & $\begin{array}{l}\text { 15. Releasing from repetitive and mundane } \\
\text { tasks }\end{array}$ \\
IMPACT ON & $\begin{array}{l}\text { 16. Higher employee satisfaction } \\
\text { 17. Improved employee morale }\end{array}$ \\
EMPLOYEES & $\begin{array}{l}\text { 18. Upskilling and learning new things } \\
\text { broviding employees with more capacity to } \\
\text { be proactive and suggest improvements }\end{array}$ \\
\hline
\end{tabular}

As for the risks related to RPA implementations, PwC (2017) presents five categories of risks: executive, technical, change management, operational, and functional risks (Table 3). The speed of the robot, poor quality of input data causing multiple business exceptions has been mentioned (Hallikainen et al., 2018), as the ways robots recognize the elements of GUI are already robust, they are not entirely impervious to system issues and changes, particularly when interacting via virtualized environment (remote desktops, Citrix). Robots have no "common sense" and their results are deterministic, so any faults in the input or in the process logic will follow with the bot's replication of errors until further noticed (Lowes, 2017).

Table 3: Categories of RPA Risks (based on Gejke, 2018; Bhatnagar, 2020; Fernandez and Aman, 2018;

PwC, 2017)

\begin{tabular}{|c|c|}
\hline CATEGORY & RPA RISKS \\
\hline EXECUTIVE & $\begin{array}{ll}\text { 1. } & \text { More rigid organization } \\
\text { 2. } & \text { Dependence of RPA } \\
\text { 3. Loss of expertise } \\
\text { 4. Lack of sponsorship } \\
\text { 5. Isolated goals } \\
\text { 6. No IT-Business alignment }\end{array}$ \\
\hline TECHNICAL & $\begin{array}{l}\text { 7. Integration } \\
\text { 8. Fault-tolerance } \\
\text { 9. No component reusability } \\
\text { 10. Legacy apps silos } \\
\text { 11. Robot authorization } \\
\text { 12. Wrong testing approach } \\
\text { 13. Cybersecurity }\end{array}$ \\
\hline $\begin{array}{l}\text { CHANGE } \\
\text { MANAGEMENT }\end{array}$ & $\begin{array}{l}\text { 14. Employee resistance } \\
\text { 15. Wrong communication } \\
\text { 16. No understanding of the RPA concept } \\
\text { 17. No HR strategy } \\
\text { 18. Skills requirements } \\
\text { 19. Drive change only by ROI perspective }\end{array}$ \\
\hline OPERATIONAL & $\begin{array}{l}\text { 20. Quality of data } \\
\text { 21. Project leadership } \\
\text { 22. No existing, concrete measurements for } \\
\text { processes (SLAs/KPIs) } \\
\text { 23. RPA may hinder real progress } \\
\text { 24. Scalability issues } \\
\text { 25. No development in the core systems } \\
\text { 26. No component reusability } \\
\text { 27. Poor documentation } \\
\text { 28. Knowledge loss } \\
\text { 29. Human control }\end{array}$ \\
\hline
\end{tabular}




\section{Issues in Information Systems}

Volume 22, Issue 2, pp. 21-40, 2021

RPA vendors market contains over 50 software platforms, yet three of them are widely regarded as the top ones: UiPath, Blueprism and Automation Anywhere (Forrester, 2019). Vendors of RPA platforms present their products and tools to be easy to learn, use and implement, also for business workers without technical background, promoting 'citizen developer' concept (UiPath, 2018). This can be effective for basic, straightforward tasks, but in order to reach full potential of sophisticated products, professional skills are required for preparation, deployment and ongoing optimization of RPA solutions (Kirchmer, 2019) Every successful implementation requires at least basic software development background, and high-quality automation of more complex processes cannot be developed without solid skills in programming (Ström, 2017). There are two key licenses types for RPA products: 'attended' where bots respond to workertriggered actions by automatically performing certain tasks to simplify a workflow, and 'unattended' where bots automatically complete the back-office tasks at scale with minimal employee intervention, run from the controller/orchestrator (Isaac et al., 2017). When an exception or an error occurs, some human expert (supervisor of the robot) needs to troubleshoot and determine the root-cause and fix it, most often by restarting the bot so that the process can be resumed where it had stopped (Untrite, 2017).

The reported cases available in the academic literature, highlight substantial diversity when it comes to RPA governance models, engagement of IT and its impact on organizational workforce (Ivančić et al. 2019). In the Telefónica $\mathrm{O} 2$ case described by Lacity et al. (2016), the involvement of IT department was relatively big, evolving from the initial negative concerns, to positive involvement and ownership strengthened by the successful wide range implementations. Even though some of 'pure skeptics' who oppose any change because of their values and/or previous experiences (Lennerfors, 2015) was also noted. The Deutsche Telekom (DT) case presented by Schmitz et al. (2018), the role of IT department was relatively minor, limited to occasional consultation and passing information. Similarly, in the case of Nordea Bank, reported by Kedziora and Penttinen (2020), the IT department was dedicated to arranging accesses to the complex IT systems setup, as well as to improving technical elements if Nordea's RPA platform (e.g. gateways, data storage, databases, virtual private networks (VPNs), proxies, backups, and Redis caching). In some of the cases reported, RPA $\mathrm{CoE}$ has also been facilitating employees from the perspective of re-skilling and personal development, as their assignments and job profiles started to transform onto more challenging and demanding (Ratia et al., 2018). Davenport and Kirby (2015) demonstrate that robotic automation supports and proves human's role in ensuring that tasks are not always being effectively performed by systems owned by enterprise IT departments. Even though software bots can quickly reduce the number full-time employees bringing saving of the size of " 4.5 people with 1 digital workforce," (Dunlap and Lacity, 2017), the employee perceptions towards automation are still reported positive in many research samples (Gnambs and Appel, 2019), with minor threats related to jobreplacement and competitiveness at the labor market (Swanson 2019, p.1011). Interestingly, along the digital workforce transformation at multiple organizations, some new business functions and roles usually placed inside IT organization have also been identified (Table 4). 
Table 4: Employee impact on the role descriptions related to RPA (based on Singh, 2018; Dunlap and Lacity, 2017; Gnambs and Appel, 2019)

\begin{tabular}{|c|c|}
\hline CATEGORY & EMPLOYEE IMPACT \\
\hline $\begin{array}{l}\text { ROBOT } \\
\text { CONTROLLER }\end{array}$ & $\begin{array}{l}\text { 1. Manager of the robots and primary point of } \\
\text { contact } \\
\text { 2. Takes care of scheduling of the robots, monitors } \\
\text { processing and signals potential issues }\end{array}$ \\
\hline BUSINESS USER & $\begin{array}{l}\text { 3. Employees that handle the exceptions generated } \\
\text { by the robot }\end{array}$ \\
\hline $\begin{array}{l}\text { PROCESS } \\
\text { ROBOTICS } \\
\text { DEVELOPER AND } \\
\text { MAINTENANCE }\end{array}$ & $\begin{array}{l}\text { 4. Develops objects and processes within the } \\
\text { process robotics application } \\
\text { 5. Maintains modelled processes in case of changes } \\
\text { within applications } \\
\text { 6. Is first point of contact for robot controller in } \\
\text { case of issues }\end{array}$ \\
\hline $\begin{array}{l}\text { TECHNICAL } \\
\text { APPLICATION } \\
\text { MANAGER }\end{array}$ & $\begin{array}{l}\text { 7. Installs and maintains process robotics software } \\
\text { (server/virtual desktops infrastructure/local) } \\
\text { 8. Maintains the system and security settings } \\
\text { 9. Monitors if applications are running }\end{array}$ \\
\hline $\begin{array}{l}\text { VENDOR } \\
\text { SUPPORT }\end{array}$ & $\begin{array}{l}\text { 10. Support in technical maintenance of the process } \\
\text { robotics software and high priority issues }\end{array}$ \\
\hline
\end{tabular}

\section{Research Design}

The research approach assumed in the paper is a combination of qualitative case study, basic qualitative study, and grounded theory. It followed the interpretive and critical reasonings (Orlikowski and Baroudi, 1991; Mingers, 2001), being primarily inquiry-oriented (Kyle, 1980), as the purpose of the research was to explore new perspectives on how the digital transformation with use of RPA affects enterprise operations. According to Merriam and Tisdell (2015) the applied research is designed to improve the practice quality, and the main purpose in the evaluation research is to form a basis for business decision making by collecting data on the value of a process, technique or program. In this paper, the focus is to develop insights about the patterns considering the process of RPA solutioning and decision making. Strengthening the practical perspective in the study was achieved by the professional experience of one of the authors, who at the moment of finalizing the paper, has been working for over 2,5 years at one of the renowned Nordic 


\section{Issues in Information Systems}

Volume 22, Issue 2, pp. 21-40, 2021

providers of Intelligent Automation services, directly involved in modelling and deploying RPA solutions for enterprises from Nordic and Central Europe, focusing on facilitation of their sustainable digital transformation.

The research data was mostly collected from interviews that took place between 2018-2019, since despite there was a limited amount of academic material available on the RPA phenomenon, researchers managed to find business experts who work on the subject and have insights on the studied research problem. Taylor et al. (2016). described qualitative interviewing to be unstructured, nondirective, non-standardized, and open-ended interviewing. Therefore, the interviews were prepared with material analysis where the documents have been provided by the interviewees. The four transcripts in question, later referred as research documents, were compiled from three organizations, and included detailed information on best practices how these organizations are choosing tasks to be automated. According to Bowen (2009) documents differ from interview data, as documents contain images and text that have been compiled without a researcher's intervention, and often these documents provide supplementary research data. The interviews were conducted as semi-structured interviews, which means that the questions were flexibly formulated, or the interview has been a be a mix of both strictly formulated questions and more freely structure questions. (Merriam and Tisdell, 2015). The sample questions used during interviewing rounds are provided in Appendix.

The interviews took place between 17.9.18 - 11.3.19. The interviewees are employed in managerial/expert roles related to RPA and represent four different organizations based in Finland, from medical, real estate and accounting industries. All the interviewees have strong practical experience in using RPA at finance and accounting tasks and have been involved in the process of choosing the tasks suitable for automation, as well as choosing the type of RPA solution. The interviewees were holding different roles in RPA teams, from top managers to coders, as well as human resource experts. In this paper, the interviewees are referred as $\mathrm{P} 1, \mathrm{P} 2, \mathrm{P} 3$ etc. to $\mathrm{P} 8$.

Table 5: Interviewee's profiling details

\begin{tabular}{|l|l|l|}
\hline $\begin{array}{l}\text { INTERVIEWEE } \\
\text { CODE }\end{array}$ & $\begin{array}{l}\text { POSITION IN } \\
\text { ORGANISATION }\end{array}$ & $\begin{array}{l}\text { INTERVIEW TIME } \\
\text { (MINUTES) }\end{array}$ \\
\hline P1 & RPA Developer & 40 \\
\hline P2 & Product owner & 47 \\
\hline P3 & Personnel manager & 30 \\
\hline P4 & Head of intelligent automation & 40 \\
\hline P5 & Senior manager & 40 \\
\hline P6 & Service manager & 40 \\
\hline P7 & Product owner & 45 \\
\hline P8 & Specialist & 35 \\
\hline & Total time & 317 minutes (5 hours \& 17 min) \\
\hline
\end{tabular}




\section{Issues in Information Systems}

Volume 22, Issue 2, pp. 21-40, 2021

Two interviews were conducted in person, face-to-face and the remaining six were conducted online via Skype for Business. The meetings were conducted in Finnish and then findings translated to English. The interviews were booked for one hour and their duration varied between 35 to 47 minutes, total length of interviews was 317 minutes, i.e. 5 hours and 17 minutes. All interviews were transcribed. The content analysis was the complex process of organizing information into several categories related to the central research questions (Bowen, 2009). Document analysis included skimming, reading, and interpretation. This process combined elements of thematic analysis and content analysis, as the document analysis can be understood as a complementary collection procedure supported by triangulation and theory building (Bowen, 2009).

\section{Results}

This section presents the findings, organized as answers to research questions.

\section{RQ1: What was the influence of IT department on RPA development?}

The observed organizations differed quite dramatically judged by their RPA development process as both bottom-up and top-down approaches to robotic process automation were evident in our data. In one of the organizations, the citizen developers were clearly the promoters of RPA. The impetus of the development work was to increase their personal productivity or that of the team through automating the tasks the citizen developers had first-hand knowledge of. In most cases reported, the implementation was performed by internal resources, yet in 3 of them, it was done by the external providers. The IT department was only involved in the installation and maintenance of the tools for RPA development, yet, had no role in actual development or maintenance of the robots. Half of organizations (4/8) reportedly had some systematic process for identifying processes that could be improved through application of RPA.

"The concept is that ideas come as widely as possible, from different sides. We come here to the workspace, and we have a list of where they are collected. We make such quick check of each idea and assess the potential of whether it works in RPA or not. And if it doesn't suit for RPA, then it will be taken elsewhere in the IS tube (from idea to solution) or will get redirected elsewhere, but it is not meant for that idea to stay here in our barrel to hold forever. "Informant 7

The motivation driving the automation came mostly from the top management, which either saw RPA as a means of increasing productivity or were simply exercising mimetic isomorphism (Dimaggio and Powell, 1983), imitation of other organizations. All case companies also followed a formal IT development process for RPA development. The IT department was involved at least in the decision making if not in the actual development of the robots. Actual development work was variously outsourced or done inhouse either by the IT department or a separate RPA development team. Moreover, in one case, the IT department was assisting with re-skilling some employees and changing their job profiles, when they moved from business positions to the robotics unit.

\section{RQ2: What decision criteria are used for RPA development?}

All of the interviewed companies reported similar development goals and development criteria, aiming for similar benefits as a result of RPA implementation. RPA was applied first and foremost to increase productivity through eliminating manual labor in highly repetitive tasks. Nonetheless, robots are never able to fully replace human workforce, in any business domain and indutsty (Tuisku, 2019). Accordingly, the number of workspaces of full-time equivalents (FTEs) the software robot was expected to eliminate was the main decision criterion for accepting the request for RPA development. It is noteworthy that only one organization reportedly applied the criteria also for choosing between the RPA requests, possibly because 


\section{Issues in Information Systems}

Volume 22, Issue 2, pp. 21-40, 2021

RPA is still a relatively new technology for most organizations, the investments in RPA are still growing, and the development backlog for RPAs has not yet grown to become a problem of its own.

"In other words, the aim is to achieve cost savings, i.e. to free up staff skills for expert tasks and then again to automate such easier routine tasks. "Informant 3

To the contrary, some interviewees expressed a degree of exasperation as they found it difficult to identify sufficiently many uses for software robots to meet the top-level management's push for increased application of RPA. These cases are reflective of mimetic isomorphism at work at the top-level management of the said companies. As it often happens, the management team is afraid of their company falling behind competition in application of a new technology. The mere sight of other companies experimenting with the technology is sufficient to prompt the management to act without having a clear picture of the capabilities and proper applications of the technology.

"Here's pretty interesting stuff, just like even bringing the event driven technology trend. (...) it is kind of what automation seeks is that we want to achieve more in less time, reduce costs and eliminate mistakes. "Informant 5

Another outcome of using only the FTE criterion for decision making is that strategic applications of RPA were entirely missing in our data set even though some interviewees hinted at other benefits than increase productivity, such as more timely information for decision-making and new insight in the quality of the data itself as the employees, now freed from the repetitive manual labor by the software robots, spend their work hours increasingly inspecting the work of the robot and, in particular, chasing and solving the exceptions, which the robot has failed to process successfully.

\section{RQ3: What are the risks are related to RPA implementation?}

The organizations interviewed were clearly divided into two groups judged by their view on RPA related risks. Those, who used software robots in relatively limited numbers and for limited tasks, such as account reconciliation of periodical reporting, did not experience substantial RPA related risks past normal IS related security risks. Those, who had applied RPA more extensively $(4 / 8)$, had realized that software robots are relatively vulnerable to large-scale problems such as the robot malfunctioning because of updates to the underlying systems.

"I don't think we've figured out yet how much time it takes (...) when it comes to an update, a system update, a pdf update, an excel update, it requires quite a bit of testing and re-coding and that they run that are in production and scheduled as they work. "Informant 1

The main problem with malfunctioning software robots in large-scale applications is that the organization has to prepare for going back to using manual labor to do the job of the malfunctioning robot. Keeping workforce in reserve for such occasions, of course, would negate the cost savings of the robots, at least for the period it takes to fix the robot and put it back into production. The interviewees well realized that software robots are particularly vulnerable to such malfunctions because of their high dependence on several layers of underlying systems.

"The work instructions are precise, and it is still preserved how a human does and what a robot brings to it. And yes, new employees are taught what to do even if the robot does it, just in case. It is ensured that you know how to do it manually. Yes, there was already little concern if the old employees were not replaced by anyone or the like. "Informant 1

\section{RQ4: How independently do software robots in process automation work?}

All of the interviewees, who explicitly discussed the extent of automation (i.e. $4 / 8$ persons), told us that, up to now, their organizations have automated, with robots, solitary steps of processes rather than even attempting to automate the whole process from end to end. Some interviewees $(1 / 8)$ were of the opinion 


\section{Issues in Information Systems}

Volume 22, Issue 2, pp. 21-40, 2021

that RPA will remain confined to automating solitary steps of work processes rather than automating the whole process from end to end. They emphasized that the current RPA implementations are not instances of artificial intelligence (AI). Rather, the robots manage relatively limited tasks, which are typically highly repetitive. Further, the robots can take care of the typical cases only as manual labor is used for exception handling.

"Let's start with the very first routine tasks, and as we move robotics forward, we will definitely have machine learning at some point, artificial intelligence at some time, yet these have their own nuances. I think all three together will revolutionize our environment in the next five years. "Informant 5

Others (3/8), though, saw removal of all manual labor in the process through automation as the next logical step. These interviewees expressed that end-to-end automation involves extensive exception handling, which in turn requires self-improving algorithms, i.e. machine learning or some other type of artificial intelligence. Recovery from erroneous data in the underlying systems, such as an invalid cost center identifier in the RPA input was given as an example of such complex exception handling. In sum, we can say that the majority view among the RPA experts seems to be that RPA development is on path toward end-to-end process automation, yet this trend is conditioned on self-improving algorithms being developed for effective exception handling.

\section{Conclusions}

This section is concluding findings from the field work and comparing them against the reviewed literature. Later, it addresses its theoretical and practical implications, as well as limitations and recommendations for future research.

There was no uniform role of IT department in the RPA development. Some implementations were based on citizen developers, while in other organizations, IT department was involved in identification of processes for improvement, following the path used for other IT systems implementations. Thus, RPA was not different from other systems and earlier experiences could be used to identify, improve, and automate processes. The implementation was in some cases outsourced to external companies or completed by internal teams. Moreover, in one case company, the IT department was also facilitating the job profile change of some employees who moved from the business side to the RPA CoE inside organization. Such practices have also been formerly reported in the literature.

When looking at decisions made by enterprises to implement RPA, those were mainly aiming at realization of benefits such as increased productivity through eliminating labor in highly repetitive tasks, reflected in reduction of person-years/FTEs. This was already identified in earlier research (Lawson, 2016; Sengupta et al., 2017; Lowes et al., 2017; Singh 2018; Jimenez and Ramirez, 2019). When the decision was made, the second stage was to identify processes that will deliver the highest benefits. There was also pressure from the market, when the competitors were implementing RPA that accelerated also other companies to follow -RPA implementation become the market standard and trend. This is no different from other new technologies disrupting Information Systems, such as cloud computing, or e-procurement (Piotrowicz and Irani, 2010). What is interesting in case of RPA, the focus on operational benefits was dominating, such the reduction of work force and increase in efficiency, yet there was some evidence that also strategic, intangible, and non-financial benefits were considered, including better data quality and timely access to information for decision making purposes, and these benefits were also mentioned earlier in literature (improved management information). Interviewees did not mention any customer-related benefits, which suggest that the implementation was focused on internal, back-office processes, without consideration of wider impact. Impact on employees was also considered, as listed earlier in the literature (Table 2), though not all the impacts were listed. While there was consideration of removal of repetitive tasks, impacts such as employee satisfaction, were not mentioned. 


\section{Issues in Information Systems}

Volume 22, Issue 2, pp. 21-40, 2021

Risks identified in the case companies were related to the level of RPA application. Organizations with minimal usage did not consider any risks, beyond typical technology functioning. Though the second group, more advanced users recognized increased dependence on the RPA, which was already mentioned in the literature. There was recognized problem of how to return to manual labor in case of technology failure, which again is not different to other systems. Similarly, as in case of benefits, there was little on strategic impact, for example on how robot malfunctioning will influence customer service or financial reporting. There is also different view of RPA among companies, while some are aiming at automating large part of the process soonest possible, whereas for others, RPA is a tool to support traditional workforce while automating repetitive tasks.

Our findings suggest that RPA is mainly perceived as an operational tool to automate and improve internal processes with little consideration of its strategic and external impact, including impact on customers and service quality. This is in line with the approach to the way of how benefits are calculated, looking mainly at savings on labor costs. As for main contributions to RPA theory, in contrast to cases previously reported in available literature, the key decision factors behind RPA deployments were operational benefits, with minor role of strategic, intangible, and non-financial aspects. As RPA become a disruptive technology, its strong impact on the global services market got identified in the decision factor of following the market trend and competitive pressure from other organizations that widely implemented RPA. Such dimension cannot be assessed as mature and efficient in the context of factors influencing IS evaluation (Piotrowicz and Cuthbertson, 2009). Conscious and productive implementation of RPA technology offers practical implications for decision makers that need to consider its impact on employees, commercials, and sustainable development goals of their organizations. The study offers practitioners aggregate insight onto the importance and role of benefits and risks driving RPA deployments that shall help them in the complex decision-making process.

Our investigation was limited by time, location, and the number of case companies where the research was conducted. It was strictly focused on the practical perspective of the aspects taken into consideration by business practitioners engaged in the decision-making process on RPA implementation at the enterprise. Thus, for the future research we recommend exploring how RPA is changing the market position of the company, influencing customer service, process quality, as well as the ability to change processes at request (how flexible can RPA be in management). Such problems could be explored using both case study, as well as quantitative, survey instruments. Moreover, in the context of demanding change management of RPA implementations having substantial impact on employees, it is also recommended to further explore the governance and effectiveness of communications related to RPA projects, as well as relations between software robots and humans forming 'hybrid workforce' together. There is also a question about regional, or sectoral differences, so the comparative, multi case study could be applied to analyze of how different organizations are approaching RPA.

\section{References}

Aguirre, S. \& Rodriguez, A. (2017). Automation of a business process using robotic process automation (RPA): A case study. In: J. Figueroa-García, E. López-Santana, J. Villa-Ramírez, R. Ferro-Escobar (Ed.) Applied Computer Sciences in Engineering. WEA 2017 Communications in Computer and Information Science, vol 742. Springer, Cham, 65-71.

Aldin, L. \& de Cesare, S. (2011). A literature review on business process modelling: New frontiers of reusability. Enterprise Information Systems, 5(3): 359-383.

J. Villa-Ramírez, R. Ferro-Escobar. vol 742. Springer, Cham, 65-71. 


\section{Issues in Information Systems}

Volume 22, Issue 2, pp. 21-40, 2021

Anagnoste, S. (2018). Robotic Automation Process - The operating system for the digital enter-prise" in Proceedings of the International Conference on Business Excellence, 12(1): 55-69

Anthony Jnr, B. (2021) Managing digital transformation of smart cities through enterprise architecture - a review and research agenda, Enterprise Information Systems, 15:3, 299-331

Asatiani, A. \& Penttinen. E. (2016). Turning robotic process automation into commercial success - Case OpusCapita, Journal of Information Technology Teaching Cases, 6(2): 67-74.

Afsarmanesh, H., Sargolzaei, M. \& Shadi, M. (2015). Semi-automated software service integration in virtual organisations. Enterprise Information Systems, 9(5-6): 528-555.

Barnett, G. (2015). Robotic process automation: adding to the process transformation toolkit. https://www.blueprism.com/uploads/resources/white-papers/RPA-Adding-to-the-processautomation-toolkit.pdf

Battilana, J. \& Lee, M. (2014). Advancing Research on Hybrid Organizing - Insights from the Study of Social Enterprises. The Academy of Management Annals. 8(1): 397-441

Beheshti, H. \& Beheshti, C. (2010). Improving productivity and firm performance with enterprise resource planning. Enterprise Information Systems, 4(4): 445-472.

Bhatnagar, N. (2020). Role of robotic process automation in pharmaceutical industries. In: A. Hassanien, A. Azar, T. Gaber, R. Bhatnagar, M. F. Tolba. (Eds.) The International Conference on Advanced Machine Learning Technologies and Applications (AM-LTA2019). AMLTA 2019. vol 921. Springer, Cham, 497-504.

Blue Prism (2019). Software Robots: Introducing the Virtual Workforce. Retrieved June 12, 2021 from: https://www.blueprism.com/about-us.

Bowen, G. A. (2009). Document Analysis as a Qualitative Research Method, Qualitative Research Journal, 9(2): $27-40$.

Bygstad, B. (2016). Generative innovation: a comparison of lightweight and heavyweight IT, Journal of Information Technology. 32(2): 180-193.

Byrne, D., Oliner, S. \& Sischel, D. (2013) Department of Labor, Goldman Sachs Global Investment Research. Retrieved June 12, 2021 from https://www.goldmansachs.com/reports

Brady, M. (1985). Artificial intelligence and robotics. Artificial intelligence, 26(1): 79-121.

Capgemini (2020). Finnish RPA market survey, Retrieved June 12, 2021 from https://www.capgemini.com/fi-en/events/findings-of-the-finnish-rpa-market-study-and-theirimplications-on-rpa-market-development/

Cewe, C., Koch, D. \& Mertens, R. (2018). Minimal Effort Requirements Engineering for Robotic Process Automation with Test Driven Development and Screen Recording. In: E. Teniente and M. Weidlich (Eds.) BPM 2017 Workshops, LNBIP 308, Springer, 642-648. 


\section{Issues in Information Systems}

Volume 22, Issue 2, pp. 21-40, 2021

Cho, E. \& Jung, Y. (2018), Consumers' understanding of autonomous driving, Information Technology \& People, 31(5): 1035-1046.

Davenport, T. H. \& Kirby, J. (2015). Beyond Automation. Harward Business Review. 58-60. Retrieved June 12, 2021 from https://hbr.org/2015/06/beyond-automation

Dimaggio, P. J., \& Powell, W. W. (1983). The iron cage revisited: Institutional isomorphism and collective rationality in organizational fields. American Sociological Review, 48(2): 147-160.

Dunlap, R. \& Lacity, M. (2017). Resolving tussles in service automation deployments: service automation at Blue Cross Blue Shield North Carolina (BCBSNC), Journal of Information Technology Teaching Cases. 7(1): 29-34

Fernandez, D. \& Aman, A. (2018). Impacts of robotic process automation on global accounting services, Asian Journal of Accounting and Governance. 9, 123-132.

Forrester (2017) The Forrester Wave ${ }^{\mathrm{TM}}$ : Robotic Process Automation, Q1 2017 - The 12 Providers That Matter Most and How They Stack Up, Forrester Research, Inc., Retrieved June 12, 2021 from https://www.forrester.com/report/The+Forrester+Wave+Robotic+Process+Automation+Q1+2017 /-/E-RES131182

Fung, H.P. (2014). Criteria, Use Cases and Effects of Information Technology Process Automation (ITPA). Advances in Robotics \& Automation. 3,3. Retrieved June 12, 2021 from https://papers.ssrn.com/sol3/papers.cfm?abstract id=2588999

Gnambs, T. \& Appel, M. (2019). Are robots becoming unpopular? Changes in attitudes towards autonomous robotic systems in Europe. Computers in Human Behavior. 93, 53-61.

Güner, E.O., Han, S., \& Juell-Skielse, G. (2020). Robotic Process Automation as Routine Capability: A Literature Review. Research Papers. 153.

Gregory, J. \& Nussbaum, K. (1982). Race Against Time: Automation of the Office: An Analysis of the Trends In Office Automation And The Impact On The Office Workforce, Office Technology and People, 1(2), 197-236.

Haliva, F. (2015) 3 Criteria to choosing the Right Process to Automate. Blog on KryonSystems. Retrieved June 12, 2021 from http://blog.kryonsystems.com/rpa/3-criteria-to-choosing-the-right-process-toautomate

Hallikainen, P., Bekkhus, R. \& Pan, S. L. (2018). How OpusCapita used internal RPA capabilities to offer services to clients, MIS Quarterly Executive. 17(1): 41-52.

Harmon, P. (2014) Business Process Change: A Business Process Management Guide for Managers and Process Professionals. 3rd Edition. Morgan Kaufman Publishers.

Harrast, S. A. (2020). Robotic process automation in accounting systems. Journal of Corporate Accounting \& Finance, 31(4), pp. 209-213 


\section{Issues in Information Systems}

Volume 22, Issue 2, pp. 21-40, 2021

Hong, H., Yin, Y. \& Chen, X. (2016). Ontological modelling of knowledge management for humanmachine integrated design of ultra-precision grinding machine. Enterprise Information Systems, 10(9), 970-981.

Horlacher, A. \& Hess, T. (2016) What does a Chief Digital Officer do? Managerial tasks and roles of a new C-level position in the context of digital transformation, 49th Hawaii International Conference on System Sciences, Honolulu, HI, pp. 5126-5135.

Issac, R., Muni, R \& Desai, K. (2018). Delineated Analysis of Robotic Process Automation Tools. 1-5.

Ivančić L., Suša V. D. and Vukšić V. (2019) Robotic Process Automation: Systematic Literature Review. In: Di Ciccio C. et al. (Eds) Business Process Management: Blockchain and Central and Eastern Europe Forum. BPM 2019. Lecture Notes in Business Information Processing, vol. 361. Springer, Cham

Jeston, J. (2018) Business Process Management: Practical Guidelines to Successful Implementations, London; New York : Routledge, Taylor \& Francis Group

Jimenez-Ramirez, A., Reijers, H. A., Barba, I., \& Del Valle, C. (2019). A method to improve the early stages of the robotic process automation lifecycle In: P. Giorgini and B. Weber. (Eds.) Advanced Information Systems Engineering. 446-461.

Jung, J., Badica, C., Nguyen, N. \& Slowinski, R. (2015). Editorial: Semantic interoperability for automated enterprises. Enterprise Information Systems, 9(3), pp. 300-302.

Kedziora, D. \& Kiviranta, H.M. (2018) Digital sales value co-creation with robotic process automation (RPA) of the finance and accounting industry in Northern and Central Europe. Management, 13(2), 161-174.

Kedziora, D. \& Penttinen, E. (2020). Governance models for robotic process automation: The case of Nordea Bank. Journal of Information Technology Teaching Cases. 11(1): 20-29

Kerremans M. (2019). Gartner market guide for process mining. Report G00353970. Gartner. Retrieved June 12, 2021 from https://www.gartner.com/en/documents/3939836/market-guide-for-process$\underline{\text { mining }}$

Kirchmer, M. (2017). Robotic Process Automation - Pragmatic Solution or Dangerous Illusion? BTOES Insights (Business Transformation and Operational Excellence Summit Insights). Retrieved June 12, 2021 from https://insights.btoes.com/risks-robotic-process-automation-pragmatic-solution-ordangerous-illusion- $0-0$

Kyle Jr., W.C. (1980). The distinction between inquiry and scientific inquiry and why high-school students should be cognizant of the distinction, Journal of Research on Science Teaching, (17:2): 123-130.

Lacity, M. \& Willcocks, L.P.: (2016) Robotic process automation at telefónica O2., MISQ Executive. 15, 21-35.

Lawson, E. (2016). The robots are here - Meet your digital workforce. A Deloitte report. Retrieved June 12, 2021 from https://www2.deloitte.com/content/dam/Deloitte/at/Documents/technology/2016deloitte-uk-robots-are-here-digital-workforce.pdf 


\section{Issues in Information Systems}

Volume 22, Issue 2, pp. 21-40, 2021

Lennerfors, T., Fors, P. \& van Rooijen, J. (2015). ICT and environmental sustainability in a changing society: The view of ecological World Systems Theory, Information Technology \& People, 28(4): 758-774.

Leno, V., Dumas, M., Maggi, F.M. \& La Rosa, M. (2018). Multi-perspective process model discovery for robotic process automation, CEUR Workshop Proceedings. 37-45.

Leopold, H., van der Aa, H. \& Reijers H.A. (2018). Identifying candidate tasks for robotic process automation in textual process descriptions. In: J. Gulden et al. (Eds.) Enterprise, Business-Process and Information Systems Modeling. BPMDS 2018, Lecture Notes in Business Information Processing, 318. 67-81.

Lhuer, X. \& Willcocks, L. (2017). The value of robotic process automation. Interview. McKinsey\&Company. $\quad$ Retrieved June $12, \quad 2021$ from https://www.mckinsey.com/industries/financial-services/our-insights/the-value-of-roboticprocess-automation

Lowes, P., Cannata, F., Chitre, S. \& Barkham, J. (2017). Automate this. The business leader's guide to robotic and intelligent automation. Deloitte. Retrieved June 12, 2021 from https://www2.deloitte.com/content/dam/Deloitte/us/Documents/process-and-operations/us-sdtprocess-automation.pdf

Luukkonen, I., Mykkänen, J., Itälä, T., Savolainen, S. \& Tamminen, M. (2012). Toiminnan ja prosessien mallintaminen. Tasot, näkökulmat ja esimerkit. Itä-Suomen yliopisto ja Aaltoyliopisto. Retrieved June 12, 2021 from http://epublications.uef.fi/pub/urn isbn_978-952-61-0697-7/urn isbn_978952-61-0697-7.pdf

Lyu, H. \& Zhang, Z. (2017). Incentives for knowledge sharing: Impact of organisational culture and information technology. Enterprise Information Systems, 11(9): 1416-1435.

Madakam, S., Holmukhe, R. M., \& Jaiswal, D.K. (2019) The Future Digital Work Force: Robotic Process Automation (RPA). JISTEM - Journal of Information Systems and Technology Managements, 16, $1-16$

Martinsuo, M. \& Blomqvist, M. (2010) Prosessien mallintaminen osana toiminnan kehittämistä. Tampere: Tampereen teknillinen yliopisto. 6-15 Retrieved June 12, 2021 from: https://tutcris.tut.fi/portal/fi/publications/prosessien-mallintaminen-osana-toiminnankehittamista(0fcee334-b120-4b28-9433-c996a0d24657).html

May, C. R., Mair, F., Finch, T., MacFarlane, A., Dowrick, C., Treweek, S., \& Murray, E. (2009). Development of a theory of implementation and integration: Normalization process theory, Implementation Science, 4. 1-29.

Merriam, E. \& Tisdell, J. (2015). Qualitative Research: A Guide to Design and Implementation, 4th Edition, Jossey-Bass, Wiley

Mingers, J. (2001). Combining IS Research Methods: Towards a Pluralist Methodology. Information systems research, 12(3): 240-260 


\section{Issues in Information Systems}

Volume 22, Issue 2, pp. 21-40, 2021

Nominacher, B. (2018). Process Mining and Robotic Process Automation Working As A Team. Article. E3 Magazine International. Retrieved June 12, 2021 from https://e3zine.com/2018/02/07/processmining-robotic-process-automation-rpa/

Orlikowski, W.J. \& Baroudi, J.J. (1991). Studying information technology in organizations: research approaches and assumptions. Information Systems Research, 2(1): 1-28.

Ostdick, N. (2016). The Evolution of RPA: Past, Present, and Future. Ac Retrieved June 12, 2021 from: https://www.uipath.com/blog/the-evolution-of-rpa-past-present-and-future

Patil, S., Mane, V. \& Patil, P. (2019). Social Innovation in Education System by using Robotic Process Automation (RPA) International Journal of Innovative Technology and Exploring Engineering 8(11): 3757-3760.

Piao, C., Han, X. \& Wu, H. (2010). Research on e-commerce transaction networks using multi-agent modelling and open application programming interface. Enterprise Information Systems, 4(3): 329353.

Piotrowicz, W. \& Kedziora, D. (2018). Outsourcing of Information Technology and Business Processes in Poland: Motivations and Environmental Factors, Managing Global Transitions 16(4): 307-333.

Piotrowicz, W. \& Irani, Z. (2010). Analysing B2B electronic procurement benefits - Information Systems perspective. Journal of Enterprise Information Management, 23(4): 559 - 579

Piotrowicz, W. \& Cuthbertson R, (2009). Sustainability - new dimension in information systems evaluation. Journal of Enterprise Information Management 22(5): 492-503

PwC. (2017). Robotic process automation: A primer for internal audit professionals. Retrieved June 12, 2021 from https://www.pwc.com/us/en/risk-assurance/publications/assets/pwc-robotics-processautomation-a-primer-for-internal-audit-professionals-october-2017.pdf

Rajesh, K.V.N., Ramesh, K.V.N. \& H. Rao (2018). Robotic Process Automation: A Death knell to deadend jobs? CSI Communications-Knowledge Digest for IT Community. 42(3): 10-14

Ranerup, A. \& Henriksen H. Z. (2019). Value positions viewed through the lens of automated decisionmaking: The case of social services. Government Information Quarterly. 36(4)

Ratia, M., Myllärniemi, J. \& Helander, N. (2018). Robotic process automation - creating value by digitalizing work in the private healthcare? In: Proceedings of the 22Nd International Academic Mindtrek Conference, Mindtrek. 222-227.

Reuters (2018): Robotic Process Automation (RPA) Market 2018 Key Highlights, Future Opportunities, Industry Trends, Share, Development Policies and Future Growth

Schmitz, M., Dietze, C. \& Czarnecki, C. (2019). Enabling digital transformation through robotic process automation at Deutsche Telekom. In: N. Urbach, M. Röglinger (Eds). Digitalization Cases: How Organisations Rethink Their Business for the Digital Age, Management for Professionals. Springer International Publishing, Cham, 15-33. 


\section{Issues in Information Systems}

Volume 22, Issue 2, pp. 21-40, 2021

Seasongood, S. (2017) Not just for the assembly line: A Case for Robotics in Accounting and Finance. Financial Executives International. Retrieved June 12, 2021 from https://www.financialexecutives.org/Topics/Technology/Not-Just-for-the-Assembly-Line-ACase-for-Robotic.aspx

Sengupta, R., Mehta, R. \& Dadu, A. (2017). The Digital Workforce is here - Understanding and Exploring Robotic Process Automation (RPA). Deloitte. Retrieved June 12, 2021 from: https://www2.deloitte.com/content/dam/Deloitte/in/Documents/strategy/in-strategy-innovationrpa-digital-workforce-noexp.pdf

Shelke, M. (2018). RPA with Process Mining. vElement. Retrieved June 12, 2021 from https://velement.io/rpa-with-process-mining/

Shehata, G.M., \& Montash, M.A. (2019), Driving the internet and e-business technologies to generate a competitive advantage in emerging markets: Evidence from Egypt, Information Technology \& People, 33(2), pp. 389-423.

Šimek, D. \& Šperka, R. (2019). How robot/human orchestration can help in an HR department: A case study from a pilot implementation. Organizacija. 52, 204-217.

Singh, D. (2018). Countdown to Digital Workforce: An evolution of RPA. Webinar. Techgig. Retrieved June 12, 2021 from https://www.techgig.com/webinar/Countdown-to-Digital-Workforce-Anevolution-of-RPA-1244

Slaby, J. (2012). Robotic automation emerges as a threat to traditional low-cost outsourcing. Retrieved June 12, 2021 from://www.horsesforsources.com/wp-content/uploads/2016/06/RS-1210_Roboticautomation-emerges-as-a-threat-060516.pdf

Suri V.K., Elia M. \& van Hillegersberg J. (2017). Software bots - the next frontier for shared ser-vices and functional excellence. In: I. Oshri, J. Kotlarsky, L. Willcocks (Eds.) Global Sourcing of Digital Services: Micro and Macro Perspectives. Global Sourcing by Lecture Notes in Business Information Processing, Springer, Cham, vol 306. 81-94.

Ström, T. (2017). Ohjelmistorobotiikka yrityksen prosessien kehittämisessä - Santander Consumer Finance

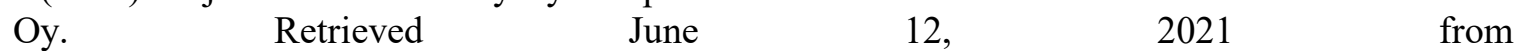
https://www.theseus.fi/bitstream/handle/10024/139524/Strom_Tomas.pdf?sequence=1

Swanson, E. B. (2019). Technology as routine capability, MIS Quarterly, 43(3): 1007-1024.

Syed, R., Suriadi, S., Adams, M., Bandara, W., Leemans, S. J. J., Ouyang, C., ter Hofstede, A. H. M., van de Weerd, I., Thandar Wynn, M. \& Reijers, H. A. (2020). Robotic process automation: contemporary themes and challenges. Computers in Industry,115(1), pp. 1-15.

Tang, Y., Xiong, J., Becerril-Arreola, R. \& Iyer, L. (2019), Ethics of blockchain: A framework of technology, applications, impacts, and research directions, Information Technology \& People, $33(2), 602-632$.

Tuisku, O., Pekkarinen, S., Hennala, L. \& Melkas, H. (2019), Robots do not replace a nurse with a beating heart: The publicity around a robotic innovation in elderly care, Information Technology \& People, $32(1), 47-67$ 


\section{Issues in Information Systems}

Volume 22, Issue 2, pp. 21-40, 2021

Untrite. (2017). Robotic Process Automation: Desktop Attended vs. Unattended on Servers. Website. Retrieved June 12, 2021 from: https://untrite.com/2017/11/robotic-process-automation-desktopattended-vs-unattended-servers/

Uwizeyemungu, S., Raymond, L., Poba-Nzaou, P. \& St-Pierre, J. (2018). The complementarity of IT and HRM capabilities for competitive performance: A configurational analysis of manufacturing and industrial service SMEs. Enterprise Information Systems, 12(10): 1336-1358

van der Aalst, W. (2011). Process mining: discovery, conformance and enhancement of business processes. vol. 2. Heidelberg, Springer.

Wilcocks, L., Lacity M. \& Craig, A. (2017) Robotic process automation: strategic transformation lever for global business services? Journal of Information Technology Teaching Cases. 7(1): 17-28

Willcocks, L., Lacity, M. \& Craig, A. (2015). The IT function and robotic process automation. In: LSE Research Online Documents on Economics from London School of Economics and Political Science, LSE Library Retrieved June 12, 2021 from: http://eprints.lse.ac.uk/id/eprint/64519

World Economic Forum. (2016) An introduction to the Digital Transformation of Industries initiative. Retrieved June 12, 2021 from http://reports.weforum.org/digital-transformation-ofindustries/anintroduction- to-the-digital-transformation-of-industries-initiative

Zhang, N. \& Liu, B. (2018). "The key factors affecting rpa-business alignment.” In: Proceedings of the 3rd International Conference on Crowd Science and Engineering. p. 10.

\section{Appendix}

Sample questions used during interviewing rounds:

1. Please describe latest RPA cases you have been involved in.

2. Describe the industries of your RPA case companies, from the perspective of KPIs and business value creation?

3. Which business processes have been automated and which ones need further optimizing and robotizing?

4. What has been the best technology for each task and process to be automatized?

5. Which automation process candidates have brought the highest benefit for the organization?

6. Which tasks has been the best cost-benefit ratio with e.g. large amount of manual or repetitive tasks, big amount of data flows or time-consuming human work with data at the moment?

7. What kind of business value RPA have brought based on already automated cases? How independently software robots work in automated processes?

8. What was the role of IT department in the development of RPA and what were the key decision criteria behind it?

9. What have been the greatest risks of robotization for the enterprise in the cases?

10. How do you see the next steps in the digital value co-creation of changing work roles and routines with RPA at financial industry? 